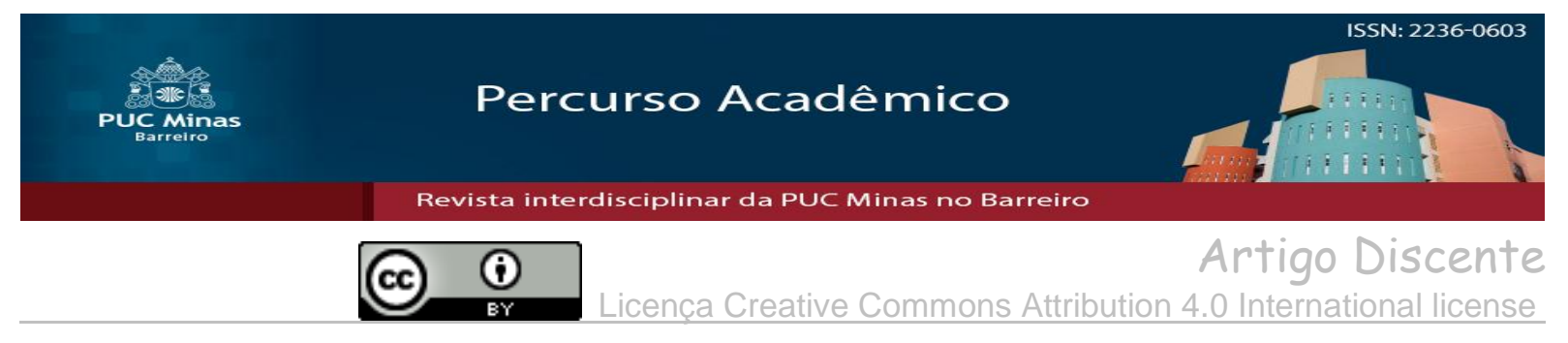

\title{
Extração da lignina presente no licor negro para adsorção de íons de metais pesados
}

\section{Extraction of lignin present in black liquor for adsorption of heavy metal ions}

Caíque Prado Machado de Oliveira ${ }^{1}$ Gustavo Henrique Arcanjo Pimenta ${ }^{2}$ Marcela Rachid Silva ${ }^{3}$ Mariana Monteiro Moraes Ramos ${ }^{4}$ Mayra do Carmo Siqueira ${ }^{5}$ Yasmim Arantes da Fonseca ${ }^{6}$

\begin{abstract}
Resumo
O crescimento médio anual de produção de papel no Brasil faz com que a produção do licor negro (subproduto do processo Kraft) aumente consideravelmente, o que se desdobra no desperdício de combustíveis e reagentes, uma vez que o licor negro apresenta composição química com considerável potencial energético e não é reaproveitado em sua totalidade pelas indústrias papeleiras. Além disso, devido a sua toxicidade este subproduto pode proporcionar danos à saúde dos seres vivos, bem como propiciar poluição ao meio ambiente. Dessa forma, com o intuito de reaproveitar esta substância, pretende-se extrair a lignina presente no licor negro e utilizá-la para adsorver íons de cobre e zinco, que são metais pesados. Esse objetivo vem a contribuir com dois caminhos atrelados a métodos sustentáveis de reaproveitamento de subprodutos da indústria química, dando a eles maior potencial econômico e tratando efluentes. O material extraído foi caracterizado quanto a volumetria de complexação, espectroscopia UV-Vis, infravermelho, MEV e foram construídas isotermas de adsorção. A análise volumétrica mostrou um potencial adsortivo do íon $\mathrm{Zn}^{2+}$ de 76,9\% em 15 minutos por parte da lignina carbonizada. As imagens do MEV evidenciaram uma estrutura de material poroso, com uma série de interstícios e fraturas superficiais. A análise do infravermelho permitiu elucidar os diferentes grupos funcionais da estrutura da lignina carbonizada que intensificam o potencial de adsorção do material.
\end{abstract}

Palavras-chaves: Licor negro. Lignina. Metais Pesados. Adsorção. Processo Kraft.

\begin{abstract}
The average annual growth of Brazilian paper production makes that the black liquor (Kraft's process sub product) production increases considerable, what goes on the waste of fuels and reagents, because the black liquor has chemical composition with appreciate energetic potential, which is not used by the paper industry in its totality. Besides that, because of its toxicity this sub product may cause living beings health damages, as well, environmental pollution. In this way, with the goal of reuse this substance, it is intended to extract the lignin present in the black liquor and use it in copper and zinc adsorption that are heavy metals. This objective contributes with two ways related to sustainable methods of chemical industries sub products reuse, giving them higher economical potential and treating effluents. The extracted material was characterized by complexation volumetry UV-Vis spectroscopy, infrared, SEM and adsorption isotherms were build. The volumetric analysis showed a adsorptive potential for the $\mathrm{Zn}^{2+}$ of $76,9 \%$ in 15 minutes by the charred lignin. The MEV images have evidenced a porous material structure, with many superficial fractures and interstitials. The infrared analysis allowed clarify the different functional groups of lignin's charred structure that are able to intensify the adsorption potential of the material.
\end{abstract}

Key words: Black liquor. Lignin. Heavy Metals. Adsorption. Kraft Process.

\footnotetext{
Artigo recebido em 13 de Abril de 2017 e aprovado em 14 de Maio de 2018.

${ }^{1}$ Mestrando em Engenharia Ambiental pela UFMG e Engenheiro Químico pela Pontifícia Universidade Católica de Minas Gerais. E-mail: caiqueoliveira@oi.com.br

${ }^{2}$ Engenheiro Químico pela Pontifícia Universidade Católica de Minas Gerais. E-mail: gustavo.arcanjo@sga.pucminas.br

${ }^{3}$ Mestranda em Engenharia Ambiental pela UFMG e Engenheira Química pela Pontifícia Universidade Católica de Minas Gerais. E-mail: marcelarachids@gmail.com

${ }^{4}$ Engenheira Química pela Pontifícia Universidade Católica de Minas Gerais. E-mail: mmmramos@sga.pucminas.br

${ }^{5}$ Engenheira Química pela Pontifícia Universidade Católica de Minas Gerais. E-mail: mayradocarmos@gmail.com

${ }^{6}$ Mestranda em Engenharia Ambiental pela UFOP e Engenheira Química pela Pontifícia Universidade Católica de Minas Gerais. E-mail: afyasmim@gmail.com
} 


\section{Introdução}

O Brasil está entre os dez maiores produtores de papel e celulose do mundo, alcançando o segundo lugar no ranking mundial de produção de celulose e o oitavo na produção de papel em 2016, de acordo com o Instituto Brasileiro de Árvores (IBÁ, 2016).

O processo Kraft, cujo objetivo é separar a fibra celulósica da madeira, é empregado na indústria para a produção de papel. Nesse contexto, a etapa de polpação gera um subproduto conhecido como licor negro, uma mistura complexa que contém grandes quantidades de substâncias orgânicas, componentes inorgânicos, reagentes não convertidos no processo Kraft e água (FORTUNATTO, 2014).

Segundo Carreiro (2009), o licor negro possui alcalinidade ativa e pode ocasionar problemas no controle biológico das estações de tratamento de efluentes e impactos severos em ecossistemas aquáticos, além de emissões de poluentes atmosféricos.

Um dos componentes do licor negro é a lignina, uma macromolécula orgânica com diversos grupos funcionais, cuja função é conferir rigidez, impermeabilidade e resistência a ataques microbiológicos aos tecidos vegetais. A lignina apresenta elevado potencial para ser empregada em diversos setores, tais como aditivo em concretos, na produção de resinas fenólicas, na indústria de cerâmicos e corantes e na geração de energia com sua queima (FENGEL; WEGENER, 1984).

Além das aplicações mencionadas, estudos recentes evidenciam o uso da lignina precipitada do licor negro como adsorvente de corantes orgânicos e metais pesados. O processo de adsorção é definido como um fenômeno físico-químico, o qual as moléculas presentes em um fluido, podendo ser este líquido ou gasoso, acumulam-se de maneira espontânea sobre a superfície de materiais sólidos (CURBELO, 2002).

Por sua vez, os metais pesados são considerados por alguns autores como sendo os metais que possuem alta massa molecular associada à sua alta toxicidade. A atividade industrial é a principal contribuinte do aumento significativo nas concentrações de íons metálicos nos ambientes aquáticos. Esses poluentes podem representar um grande risco para a saúde humana e para a natureza, uma vez que podem ocasionar alterações das características físico-químicas da água, redução da biodiversidade e contaminação de organismos vivos (SILVA, 2010).

Nesse sentido, há necessidade de minimizar o impacto destas substâncias sobre o meio ambiente acoplado com as rigorosas leis ambientais, e torna-se indispensável o tratamento de efluentes contendo tais espécies poluidoras (HAYASHI, 2001). Dessa forma, pesquisas têm 
sido desenvolvidas em busca de novas tecnologias para remover essas substâncias tóxicas, sendo a adsorção uma alternativa viável para o tratamento (JIMENEZ; BOSCO; CARVALHO, 2004).

A literatura apresenta estudos na área de adsorção utilizando a lignina como adsorvente como estudado por Sipponen et al. (2014), no qual os autores demonstram a capacidade de adsorção da lignina isolada comparativamente com outros compostos que contém a substância, como o bagaço da cana-de-açúcar, casca de aveia e palha de trigo. Neste estudo é demonstrado a eficiência desses componentes em adsorver seletivamente um corante através da adequação em isotermas no modelo de Lagmuir que comprovaram a capacidade adsorvente da lignina.

Em 2016, Berrima et al. precipitaram a lignina do licor negro valendo-se de ácido sulfúrico diluído e a carbonizaram a uma temperatura de $600^{\circ} \mathrm{C}$, formando um carvão adsorvente dos íons $\mathrm{Pb}^{2+}, \mathrm{Cd}^{2+}, \mathrm{Hg}^{2+}$ e $\mathrm{Ni}^{2+}$. Os autores compararam as características morfológicas e o comportamento cinético do material produzido com a lignina comercial e concluíram que o carvão a base de lignina pode ser utilizado como adsorvente reutilizável em processos de remoção de metais pesados.

Fu et al. (2013) estudaram o carvão ativado obtido através da lignina e demonstraram a eficiência do composto de adsorver o corante azul de metileno e dessa forma a possível aplicação desse adsorvente em águas residuárias de corantes. $\mathrm{O}$ estudo foi feito utilizando os modelos das isotermas de Freundlich; Langmuir. O trabalho ainda mostrou a eficiência do processo físico de ativação do componente que foi realizado.

Já $\mathrm{Hu}$; Chen (2015) estudaram adsorvente a base de lignina com sílica para a adsorção de íons metálicos, nanopartículas e pesticidas orgânicos em hexano. $\mathrm{O}$ adsorvente demonstrou eficiência de remoção acima de $90 \%$ para os compostos orgânicos em um tempo de 15 minutos e para íons de metais como cromo, chumbo, ferro, zinco e mercúrio a adsorção foi maior que $94 \%$ em um tempo de 10 minutos em concentrações que variaram de 1 a 3 ppm. Para nanopartículas de ouro e prata, a remoção foi próxima a 100\%. Todos esses resultados foram obtidos utilizando $20 \mathrm{mg}$ de adsorvente. O estudo ainda mostra que a origem do adsorvente, do adsorvato e as condições como $\mathrm{pH}$ do meio influenciam na adsorção dos compostos. Todos estes estudos evidenciam a viabilidade da lignina ser utilizada como adsorvente para diferentes tipos de compostos.

Norteado por essa ótica, o presente trabalho baseia-se na extração da lignina presente no licor negro e sua utilização como adsorvente de íons cobre e zinco. Esta possibilidade é motivada devido à heterogeneidade e complexidade estrutural da macromolécula de lignina, 
que apresenta ao longo da cadeia diversos pontos reativos, constituindo-se de uma nova alternativa para a remoção de metais de correntes aquosas, conforme discutido por outros autores. (GELLERSTEDT, 2012).

\section{Metodologia}

O licor negro (Fig. 1a) utilizado no presente trabalho é advindo de uma indústria de papel e celulose, sendo oriundo do processo kraft de produção do papel. A lignina (Fig. 1b), contida no licor, foi precipitada através do método descrito por Paula (2010). Para isso, adicionou-se ao licor negro $50 \mathrm{~g}$ de sulfato de sódio e ácido sulfúrico $6 \mathrm{~mol} / \mathrm{L}$ até aproximadamente $\mathrm{pH} 2$ e deixou-se o sistema em agitação por uma hora sob aquecimento de $56^{\circ} \mathrm{C}$. A separação da lignina precipitada do sobrenadante foi executada filtrando-se o sistema (Fig. 1c) com filtro $90 \mathrm{~mm}$. O material retido foi lavado com solução de ácido clorídrico $\mathrm{pH}$ 1. Secou-se a lignina na estufa a $60^{\circ} \mathrm{C}$ por uma hora.

Figura 1: (a) licor negro (b) lignina precipitada (c) filtração da lignina

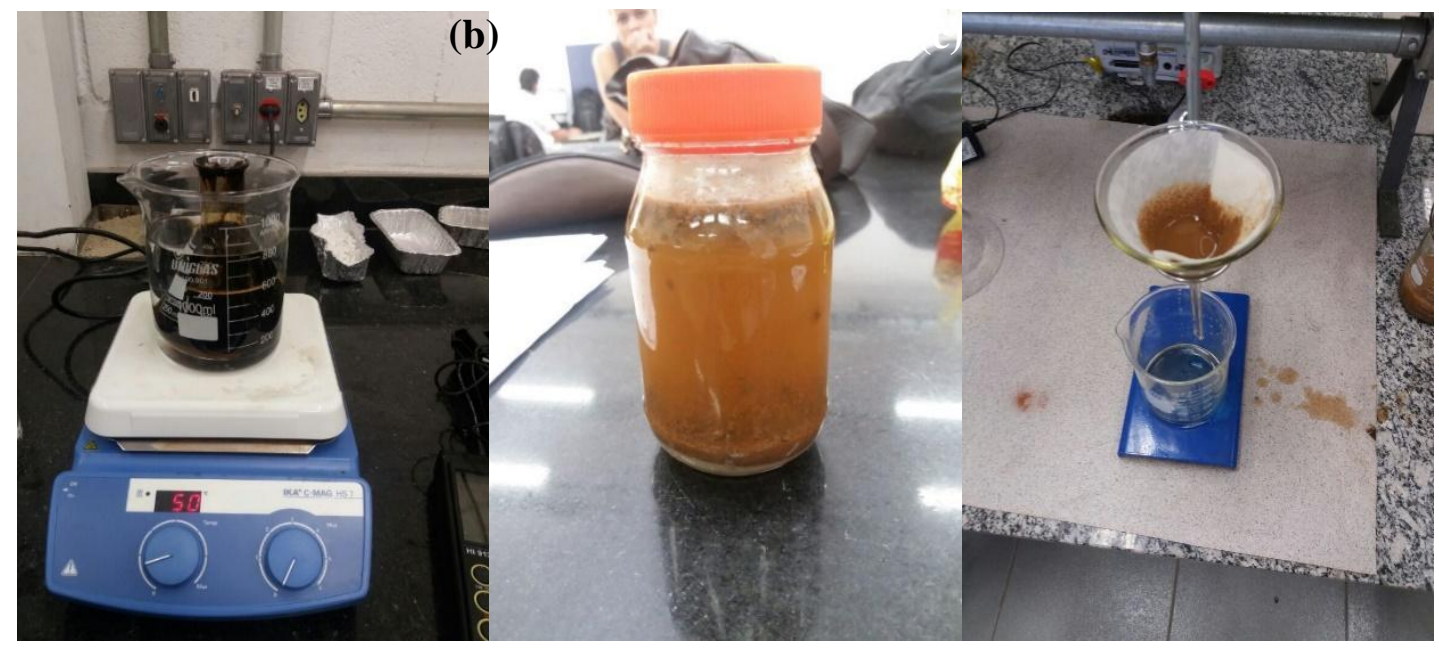

Fonte: Elaborado pelos autores

De posse da lignina filtrada, realizou-se a ativação da mesma enquanto adsorvente. Baseando-se e adaptando o método de Rodriguez-Mirasol et al. (1993), a carbonização (Fig. 2) da lignina foi efetuada sob atmosfera inerte. A amostra foi submetida a uma temperatura de $288^{\circ} \mathrm{C}$ por 2 horas sob atmosfera de $\mathrm{N}_{2}$. Findada a carbonização a tal temperatura, a amostra foi lavada com ácido sulfúrico $1 \%$ v/v. 
Figura 2: Processo de carbonização da lignina

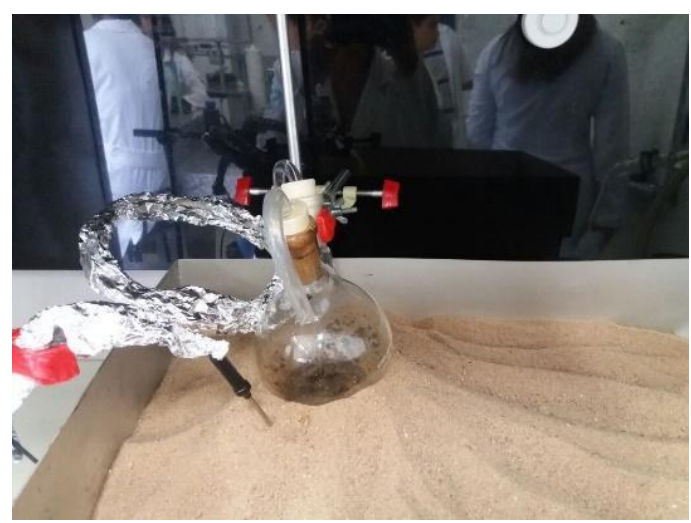

Fonte: Elaborado pelos autores

As caracterizações feitas foram: Microscopia Eletrônica de Varredura (MEV), EDS acoplado a microscopia, espectroscopia de infravermelho, bem como espectroscopia de absorção molecular (UV-Vis) e volumetria de complexação para verificar o potencial adsortivo da lignina carbonizada. O ensaio de microscopia eletrônica de varredura foi realizado nos laboratórios do Departamento de Engenharia Metalúrgica da PUC Minas, no equipamento da marca Jeol, modelo JSM-IT 300 com módulo EDS Oxford Instruments XMax 20 obtendo-se imagens com ampliação de 40, 100, 170, e 750 vezes. Já para Espectroscopia de Absorção Molecular UV-Vis utilizou-se um espectrofotômetro UV-3600 Shimadzu empregando cubetas de quartzo. A lignina carbonizada, em forma de carvão ativado, foi submetida a análise da espectroscopia em infravermelho. Nesta medida, foi utilizada um raio monocromático de luz infravermelha que passou pela amostra, registrandose assim a quantidade de energia absorvida. Repetiu-se tal operação ao longo de uma faixa de comprimentos de onda de interesse, construindo-se o espectro (Fig. 7).

Um resíduo com íon $\mathrm{Zn}^{2+}$ foi sintetizado, a partir do sulfato de zinco. Tal resíduo foi colocado em contato com a lignina carbonizada em diferentes tempos e executou-se o método volumétrico de complexação por EDTA na presença de indicador eriocromo T e meio básico, a fim de determinar a concentração da solução com o íon antes e depois do contato com o material, para se comprovar a eficiência de adsorção de metais pesados da lignina carbonizada produzida.

A fim de verificar a capacidade de adsorção do material produzido para os íons $\mathrm{Cu}^{2+}$ foram adicionadas diferentes massas de lignina carbonizada a $300 \mathrm{~mL}$ de cinco soluções de sulfato de cobre $\left(\mathrm{CuSO}_{4}\right)$ com concentração inicial de $0,4 \mathrm{~g} / \mathrm{L}$, que foram mantidas sob agitação no Jar Test e centrifugadas depois de cinco minutos de agitação. Posteriormente foram lidas as absorbâncias das amostras no comprimento de onda $596 \mathrm{~nm}$. É importante 
ressaltar que nessa etapa foi adicionado cerca de $1 \mathrm{~mL}$ em cada alíquota de Hidróxido de Amônio para a formação de um complexo azul para a leitura mais eficaz no aparelho de UVVis.

As leituras de concentração do íon $\mathrm{Cu}^{2+}$ em solução antes e após contato com a lignina carbonizada foi feita a partir do método fotométrico e a equação da reta de operação utilizada para os cálculos posteriores foi: $\mathrm{y}=0,1914 \mathrm{x}-0,001$, onde y representa a absorbância lida e x a concentração encontrada. $O$ coeficiente $R^{2}$ obtido igual a 0,9999 indica que a reta de operação está adequada para o processo. Usando a equação que a descreve, obtida via ajuste linear, foi possível determinar a concentração de equilíbrio, $\mathrm{Ce}$, de cada uma das amostras usadas na investigação do processo de adsorção. E isotermas de Freundlich e Langmuir foram construídas com base nos dados obtidos.

Figura 3: Fluxograma simplificado da metodologia

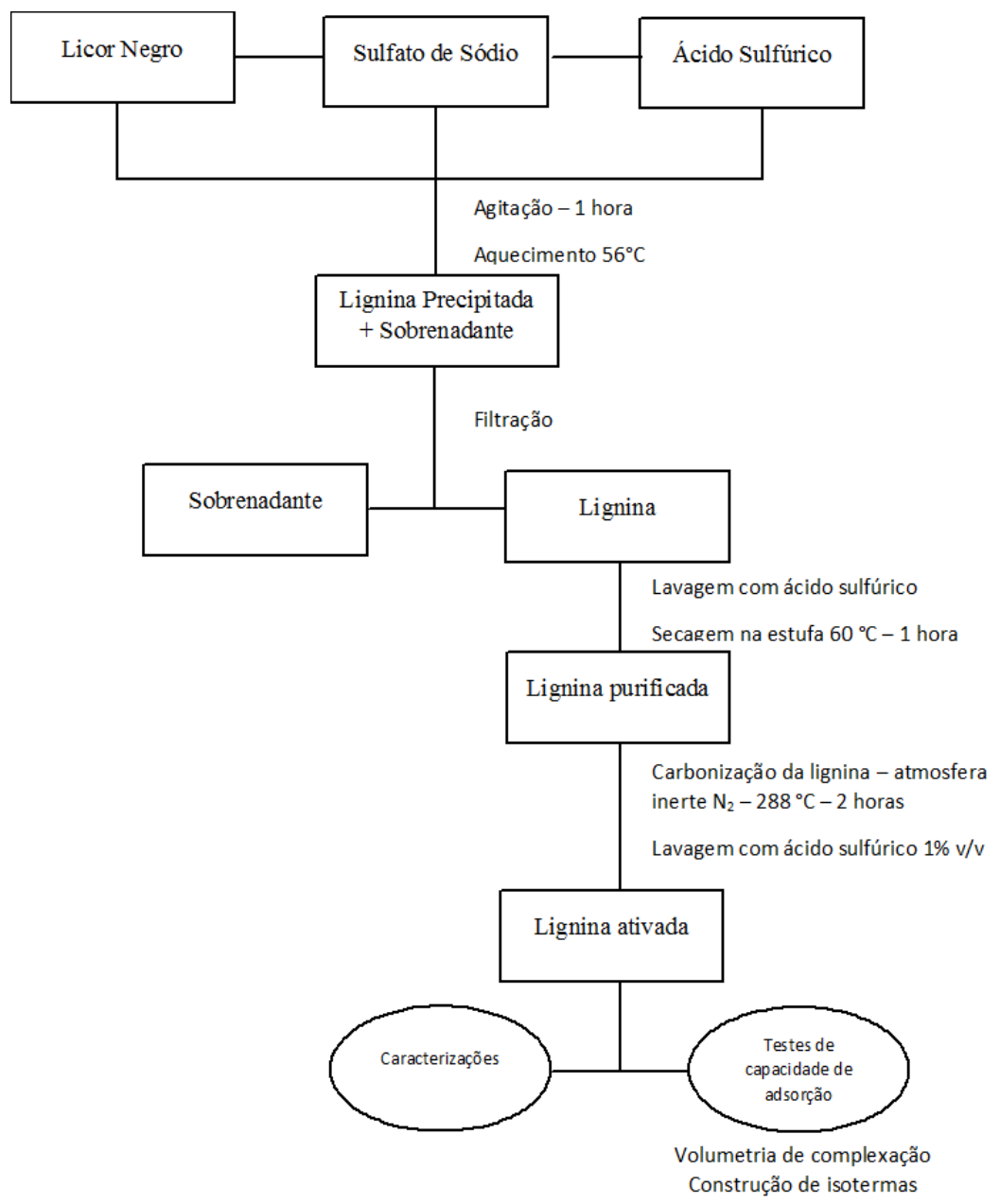

Fonte: Elaborado pelos autores 


\section{Resultados e Discussão}

\subsection{Caracterização superficial pelo Microscópio Eletrônico de Varredura (MEV)}

Figura 4: Imagens da Lignina carbonizada - MEV- em ampliação de 170 x (a) em ampliação de 750 x (b)
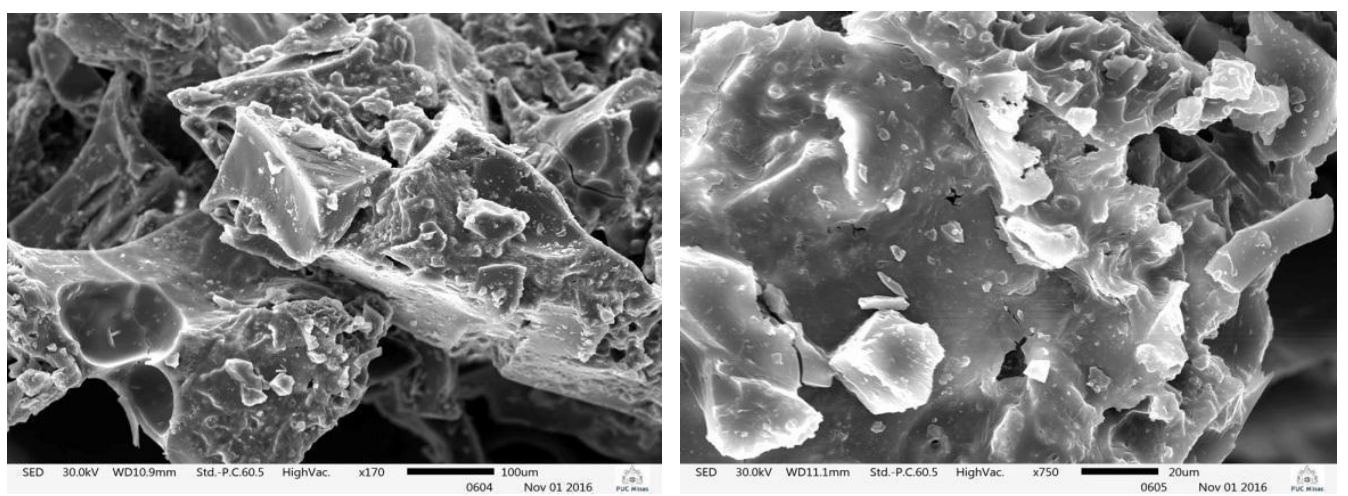

Fonte: Laboratório do Departamento de Engenharia Metalúrgica da PUC Minas

Pode-se observar pela Figura 4 (a), que a amostra aparenta estar pulverizada, pois há uma série de espaços vazios e uma estrutura disforme com bastante irregularidade. Na imagem ao lado (Fig. 4b) quando é aumentada a ampliação, é possível perceber zonas de notórias irregularidades e interstícios vazios que conferem alta porosidade e área superficial, propriedades adequadas para um processo de probabilidade de capacidade de adsorção, por constituírem sítios físicos, ou seja, conformações propícias para esse fenômeno. Esta característica disforme pode ser decorrente de resquícios da estrutura da parede celular dos compostos vegetais usados para produção de papel. Na Figura 5 são focalizadas algumas regiões com poros bem definidos na estrutura.

Figura 5: Focalização em regiões de poros da Lignina carbonizada -MEV-em ampliação de $40 \times$ (b) $100 \times$
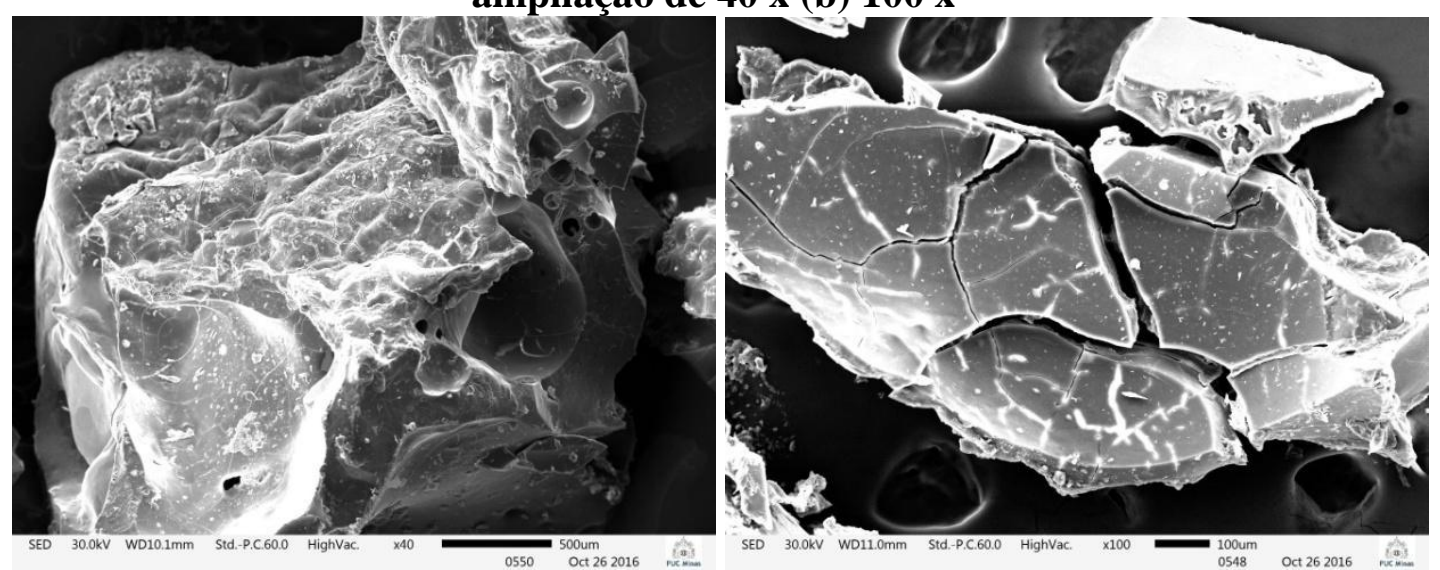

Fonte: Laboratório do Departamento de Engenharia Metalúrgica da PUC Minas 
Um dos objetivos, ao longo do estudo, foi compreender qual o mecanismo e tipo de adsorção promovida pelo material. Conforme discutido acima, é possível visualizar a presença de cavidades e estrutura irregular do material carbonizado. De acordo com Brunch (1997), uma estrutura superficial com muitos defeitos está com um desequilíbrio de forças significativo capaz de imobilizar íons ou outras espécies em sua superfície buscando a estabilidade. Contudo, assim como as interações físicas acontecem na superfície do material, as químicas também ocorrem. Desse modo, não se pode concluir qual interação é mais tônica, nesse caso.

\subsection{Espectrômetro de raios-X por Dispersão de Energia - EDS}

Acoplado aos dados obtidos pelo MEV foi apresentado o resultado do Espectrômetro de raios-X por Dispersão de Energia (EDS). A seguir está a imagem (Fig.6) que ilustra esse resultado.

Figura 6: Espectro de EDS da amostra de lignina carbonizada

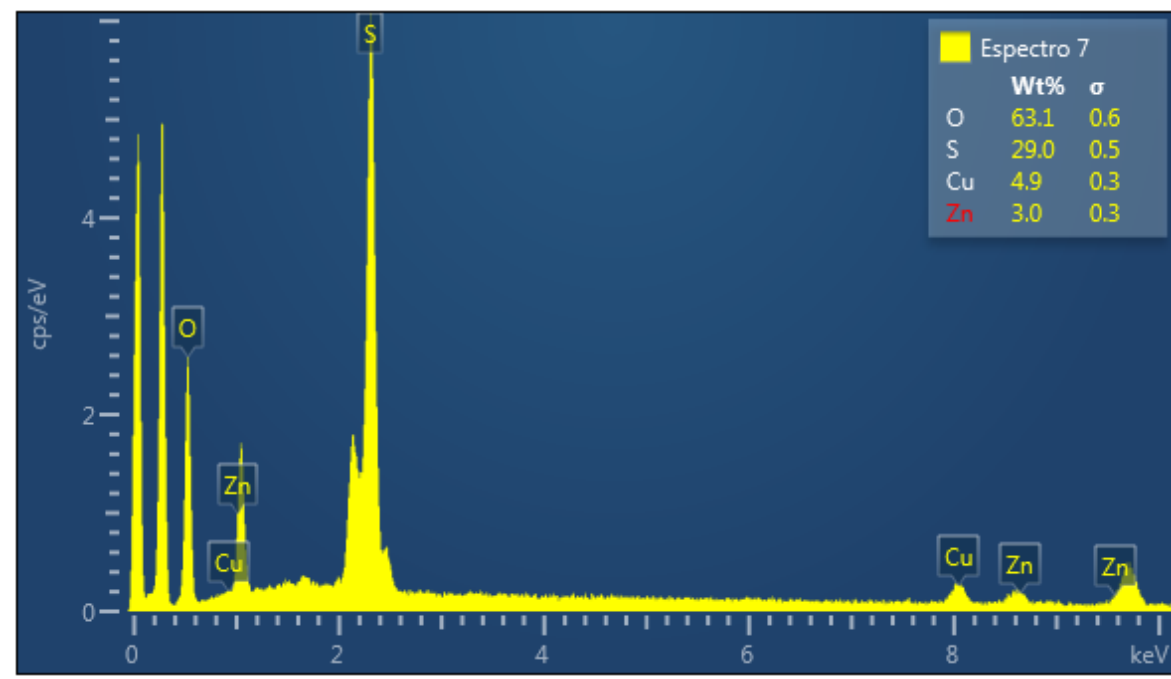

Fonte: Laboratório do Departamento de Engenharia Metalúrgica da PUC Minas

Ao analisar a Figura 6, verifica-se a presença de oxigênio, elemento abundante na estrutura da lignina. $\mathrm{O}$ enxofre tem um pico bastante acentuado e, certamente, se trata de um resquício do processo de precipitação da lignina, visto que foi usado ácido sulfúrico concentrado. Fato peculiar que essa intensidade do pico do enxofre é condizente a uma propriedade organoléptica do licor negro e da lignina carbonizada obtida do precursor mencionado: ambos apresentaram cheiro intenso de compostos característicos desse elemento. Nota-se também picos referentes aos elementos cobre e zinco, elementos que são estranhos à amostra, pois no procedimento de produção da lignina não foram utilizadas substâncias que 
apresentassem tais elementos, podendo ser provenientes de alguma contaminação durante o processo industrial da produção de papel.

A rugosidade da superfície da amostra é um fator importante que pode aumentar consideravelmente o erro da quantificação. A lignina carbonizada obtida possui uma estrutura muito irregular, dessa forma o erro referente ao resultado obtido pelo EDS tende a ser grande.

\subsection{Análise da Espectroscopia em Infravermelho}

A Figura 7 apresenta o espectro obtido na análise de Espectroscopia em Infravermelho.

Figura 7: Espectroscopia em infravermelho da Lignina carbonizada

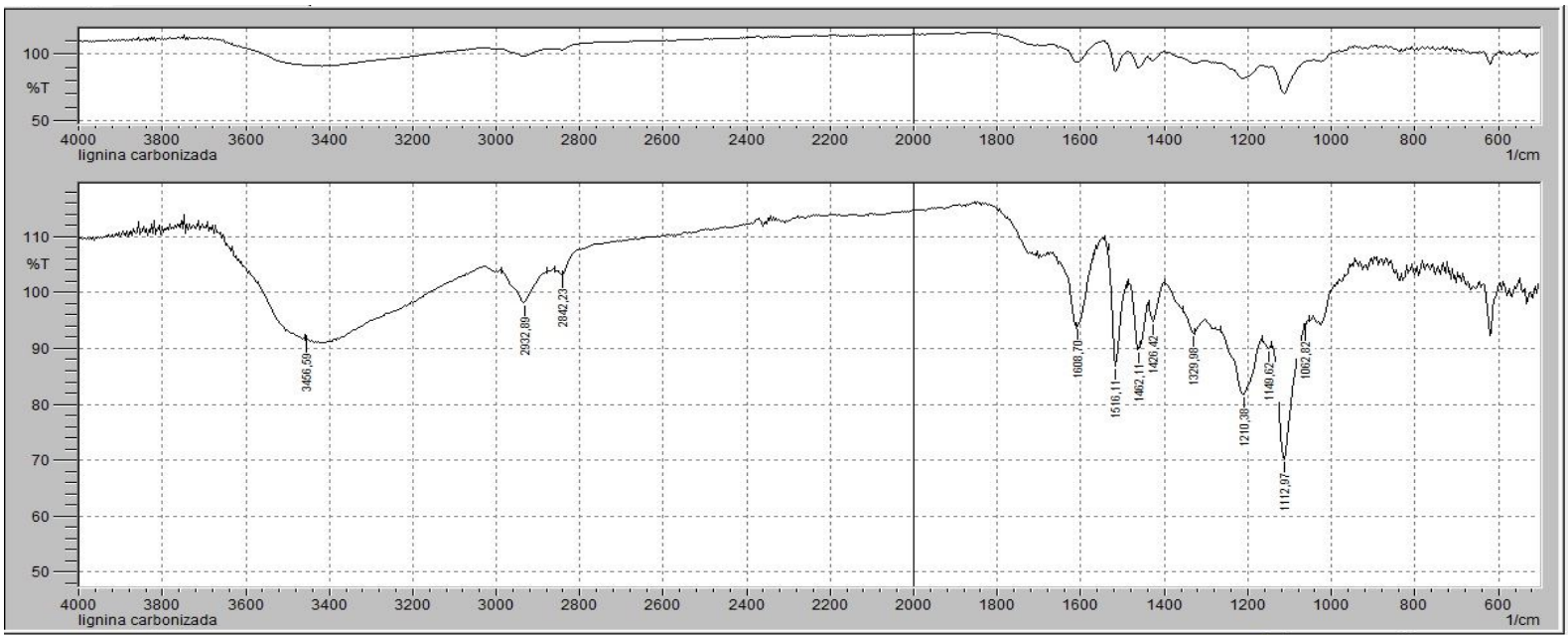

Fonte: Laboratório de Análises Instrumentais do Departamento de Engenharia Química da PUC Minas

As bandas características da lignina foram determinadas com base em Saliba et al. (2001) que definem as principais bandas e a quais grupos as mesmas são pertencentes.

As intensidades dos sinais dos espectros da lignina foram determinadas com base nos sinais na faixa de $1500 \mathrm{~cm}^{-1}$ que representam ligações entre $\mathrm{C}-\mathrm{H}$ de grupos metílicos, e pelos sinais de $1200 \mathrm{~cm}^{-1}$ e $1300 \mathrm{~cm}^{-1}$ onde Monteiro (2009) encontra as mesmas bandas que representam a ligação $\mathrm{C}-\mathrm{O}$ de anéis guaiacílicos. Pode-se ainda reparar os picos nas bandas trigêmeas de lignina para as faixas de $1515-1415 \mathrm{~cm}^{-1}$ que indicam a presença de ligações do tipo C-C de anéis aromáticos e também a baixas intensidades à 1060-1070 cm- ${ }^{1}$ que são responsáveis pela ligação entre C-O em álcoois secundários, também encontrados nos trabalhos de Abreu et al. (2010) e Barbetta (2007).

Pela análise do espectro ainda foi possível encontrar os picos vibracionais referentes ao esqueleto aromático (1500-1517 $\left.\mathrm{cm}^{-1}\right)$ e anel siringílico $\left(1315-1330 \mathrm{~cm}^{-1}\right)$ evidenciados também nos estudos de Gilarranz et al. (2001) e Ibarra et al. (2005). 
O infravermelho vem corroborar com os dados obtidos pelo MEV do potencial adsortivo do material, haja vista a quantidade de grupos funcionais presentes na amostra que só intensificam essa propriedade do mesmo.

\subsection{Volumetria de Complexação}

As eficiências de adsorção em relação ao tempo de contato do material adsorvente com a solução contendo os íons de metais pesados estão descritas na Tabela 1:

\section{TABELA 1}

Eficiência de remoção do $\mathrm{Zn}^{2+}$ de acordo com o tempo

\begin{tabular}{c|c}
\hline Tempo (minutos) & Eficiência de adsorção (\%) \\
\hline 5 & 76,2 \\
10 & 76,2 \\
15 & 76,9 \\
\hline
\end{tabular}

Fonte: Elaborado pelos autores

A análise desse resultado permite inferir que já no tempo de 5 minutos, o material havia adsorvido, em toda sua capacidade, o íon zinco, havendo pequena diferença para o tempo de 15 minutos. De todo modo, a lignina carbonizada apresentou uma eficiência média de remoção de íons de metais pesados de 76,4\%. Segundo a NBR 11834 (ABNT, 1991), filtros de carvão ativado são considerados de classe I, quando possuem eficiência de remoção de íons ou partículas superior a 75\%. Isso evidencia a relevância do valor de eficiência encontrado para a substância estudada.

\subsection{Isotermas de adsorção}

De posse do valor de $\mathrm{C}_{\mathrm{e}}$ de cada um dos sistemas, calculou-se a capacidade de adsorção do íon $\mathrm{Cu}^{2+}, \mathrm{q}_{\mathrm{e}}$. Os dados calculados encontram-se na tabela 2.

TABELA 2

Concentrações finas das soluções após o contato com o adsorvente e cálculo do qe correspondente

\begin{tabular}{c|c|c|c|c}
\hline Amostra & $\begin{array}{c}\text { Massa de } \\
\text { Adsorvente }(\mathbf{g})\end{array}$ & $\begin{array}{c}\text { Conc. Inicial } \\
(\mathbf{g} / \mathbf{L})\end{array}$ & Conc. Final $(\mathbf{g} / \mathbf{L})$ & $\mathbf{q}_{\mathbf{e}}(\mathbf{g} / \mathbf{g})$ \\
\hline 1 & 0,0303 & 0,4 & 0,3710 & 0,287 \\
2 & 0,0506 & 0,4 & 0,3553 & 0,265 \\
3 & 0,0900 & 0,4 & 0,2769 & 0,410 \\
4 & 0,1079 & 0,4 & 0,2560 & 0,400 \\
\hline
\end{tabular}

Fonte: Elaborado pelos autores 
Conhecidos todos os parâmetros do equilíbrio do processo de adsorção para cada um dos sistemas, foi feito o ajuste aos modelos de Langmuir e Freundlich.

Com esses valores foram confeccionados os gráficos para as isotermas de Freundlich (Fig. 8a) e Langmuir (Fig. 8b), respectivamente. E com os resultados das linearizações obtidas é possível determinar os parâmetros das equações das isotermas.

Figura 8: Gráficos da Isoterma de Freundlich (a) e Langmuir (b)
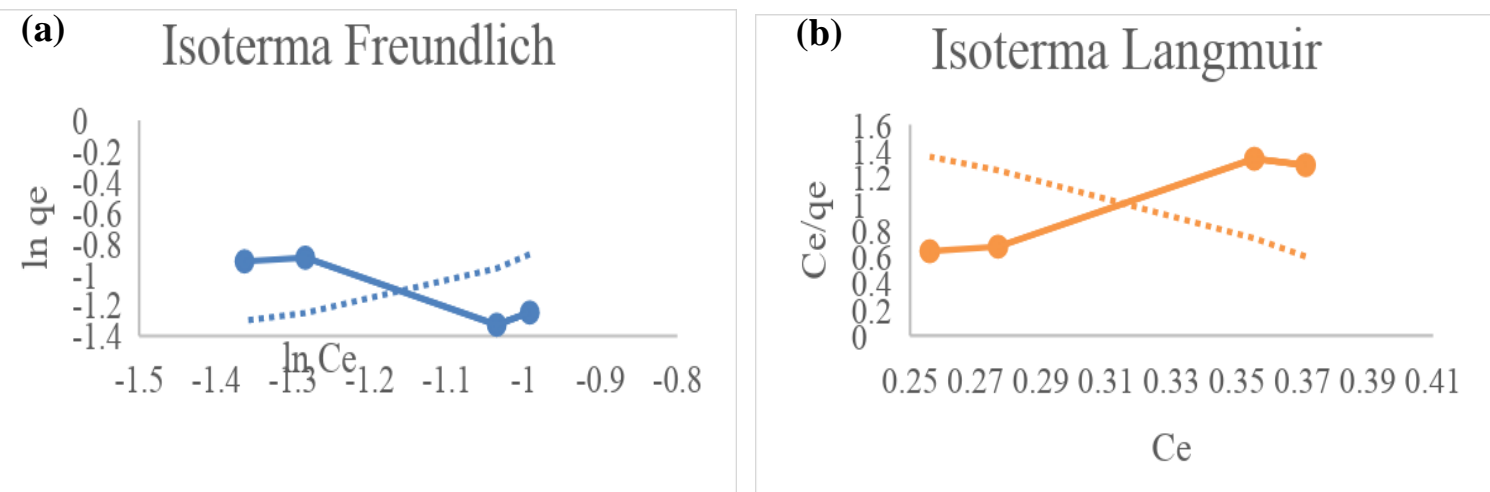

Fonte: Elaborado pelos autores

As constantes dos modelos foram: para o modelo de Langmuir $\mathrm{q}_{\max }=0,1520$ e $\mathrm{b}=6,071$, enquanto que para o de Freundlich foi encontrado K=0,086 L.g e n=-0,861.

Observando os valores de $\mathrm{R}^{2}$ obtidos, é possível afirmar que o ajuste linear que melhor representa o processo de adsorção é o ajuste obtido pela isoterma de Langmuir, uma vez que apresentou valor de 0,9605 , enquanto o modelo de Freundlich apresentou o coeficiente igual a 0,8959 .

\section{Conclusão}

As caracterizações evidenciaram que a lignina de fato foi extraída do licor negro e ratificaram o seu uso potencial como adsorvente, visto que foram observadas zonas de notórias irregularidades e interstícios vazios que conferem alta porosidade e área superficial ao material.

As análises de volumetria de complexação revelaram que a lignina carbonizada apresentou uma eficiência média de remoção de íons do metal zinco $\left(\mathrm{Zn}^{2+}\right)$ de $76,4 \%$, valor bastante significativo tendo em vista que os carvões ativados classe I possuem eficiência de remoção de partículas superior a $75 \%$.

No que diz respeito à adsorção do íon $\mathrm{Cu}^{2+}$ os dados se ajustaram melhor ao modelo da isoterma de Langmuir quando comparado ao proposto por Freundlich. Ademais, a capacidade de adsorção do íon cobre (II) também se mostrou relevante, uma vez que houve redução de 
36\% da concentração inicial da espécie no tempo de cinco minutos para uma massa de 0,1079 g de lignina carbonizada. 


\section{REFERÊNCIAS}

ABREU, Heber dos Santos et al. Evolução da lignina de gimnospermas. Abordagem Quimiossistemática e evolução química de fanerógamas. Seropédica: EDUR, 2010.

ASSOCIAÇÃO BRASILEIRA DE NORMAS TÉCNICAS. NBR 11834: Carvão ativado pulverizado - Especificação. Rio de Janeiro: ABNT, 1991.

BARBETTA, Clarissa Magalhães; MAGINI, Máira Rodrigues. Espectros eletromagnéticos na região do infravermelho: utilização na caracterização de novos materiais. Anais do $X$ Encontro Latino Americano de Iniciação Científica e VI Encontro Latino Americano de PósGraduação. Universidade do Vale do Paraíba, 2007. Disponível em:<http://www.inicepg.univap.br/cd/INIC_2006/inic/inic/07/INIC0000338ok.pdf> Acesso em: 18 set. 2017.

BERRIMA, Besma et al. Adsorption of heavy metals on charcoal from lignin. Cellulose chemistry and technology, v.50, n.5-6, p. 701-709, 2016. Disponível

em:<http://www.cellulosechemtechnol.ro/pdf/CCT5-6(2016)/p.701-709.pdf > Acesso em: 13 out. 2017

BRUNCH, Lou; COLE, Milton; ZAREMBA, Eugene. Physical adsorption: forces and fenomena. International series of monographs on chemisty. Clarendon: New York, 1997. V. 33.

CARREIRO, Milton Roberto de Mattos. Análise Energética e Ambiental do Processamento do Licor Negro Gerado em Fábricas de Celulose e Papel. Itajubá. $141 \mathrm{f}$. Dissertação (Mestrado) - Instituto de Engenharia Mecânica, Universidade Federal de Itajubá, Itajubá, 2009. Disponível em:<https://saturno.unifei.edu.br/bim/0035811.pdf> Acesso em: 19 nov. 2017.

CURBELO, Fabíola Dias da Silva. Estudo da remoção de óleo em águas produzidas na indústria de petróleo, por adsorção em coluna utilizando a vermiculita expandida e hidrofobizada. Natal, 2002. 102p. Dissertação (Mestrado) - Universidade Federal do Rio Grande do Norte, 2002.

FENGEL, Dietrich; WEGENER, Gert. Wood, chemistry, ultrastructure, reactions. New York: Waster \& Grugter, 1984.

FORTUNATTO, Ana Carla. Alternativas para o aproveitamento do licor negro da indústria de papel e celulose. Monografia (Conclusão do Curso de Especialização em Gestão Ambiental e Negócios no Setor Energético do Instituto)- Instituto de Energia e Ambiente da Universidade de São Paulo, Universidade de São Paulo, São Paulo, 2014.

FU, Kaifang et al. Preparation, characterization and application of lignin-based activated carbon from black liquor lignin by steam activation. Chemical Engineering Journal, [s.1.], v. 228, p.1074-1082, jul. 2013. Disponível em::<https://www.sciencedirect.com/science/article/pii/S1385894713006475> Acesso em: 29 out. 2017. 
GELLERSTEDT, Göran. Lignin recovery and lignina-based products. Integrated Forest Biorefineries - Challenges and Opportunities. n. 18. South Dakota, EUA: The Royal Society of Chemistry (RSC), 2013. Cap. 8, p.180-210. Disponível em: <http://pubs.rsc.org/en/content/chapter/bk9781849733212-00180/978-1-84973-321-2> Acesso em: 22 ago. 2017.

GILARRANZ, Miguel et al. Phenolic OH group estimation by FT-IR and UV spectroscopy.Application to organosolv lignins. Journal of Wood Chemistry and Technology, v.21, p.387-395. 2001. Disponível em:

<https://www.tandfonline.com/doi/abs/10.1081/WCT-100108333> Acesso em: 14 set. 2017.

HAYASHI, Angela Mitsuyo. Remoção de Cromo Hexavalente Através de Processos de Biossorção em Algas Marinhas. Tese (Doutorado) - UNICAMP, FEQ. Campinas, 2001.

HU, Shun-wei; CHEN, Shushi. A multipurpose lignin-based adsorbent for metallic ions, nanoparticles and various organophosphate pesticides in hexane. Journal Of The Chinese Chemical Society, [s.1.], v. 62, n. 10, p.875-888, 7 set. 2015. Wiley-Blackwell.

IBÁ. Indústria Brasileira de Árvores. Relatório Anual 2017. Cap.6, p.41-42, 2017.

IBARRA, David et al. Chemical characterization of residual lignins from eucalypt paper pulps. Journal of Analytical and Applied Pyrolysis, v.74, p.116-122, 2005. Disponível em:<http://digital.csic.es/bitstream/10261/39899/3/2005-Ibarra-JAAP.pdf> Acesso em: 29 jul. 2017.

JIMENEZ, Ricardo Sarti; BOSCO, Sandra Maria Dal; CARVALHO, Wagner Alves. Remoção de metais pesados de efluentes aquosos pela zeólita natural escolecita - influência da temperatura e $\mathrm{pH}$ na adsorção em sistemas monoelementares. Revista Química Nova, v.27, n. 5, p. 734-738, 17 abr. 2004.

MONTEIRO, Maria Beatriz de Oliveira. Lignificação comparativa de Eucalyptus urophylla $\mathrm{S}$. T. Blake por ferramentas biotecnológicas e polimerização in vitro. Tese de Doutorado, UFRRJ, Seropédica, 151p, 2009.

PAULA, Sara Cristina da Silva. Precipitation of lignin from kraft black liquor. Tese (Mestrado em Engenharia Química) - Universidade do Porto-Chalmers, 2010.

RODRÍGUEZ-MIRASOL, José; CORDERO, Tomás; RODRÍGUEZ, Juan José. Activated carbons from $\mathrm{CO}_{2}$ partial gasification of eucalyptus kraft lignin. Energy Fuels v.7, p.133138. Disponível em:<https://pubs.acs.org/doi/abs/10.1021/ef00037a021> Acesso em: 12 set. 2017.

SALIBA, Eloísa de Oliveira et al. Ligninas - Métodos de obtenção e caracterização química. Revista Ciência Rural, v. 31, n. 5, out. 2001. Disponível em:〈http://www.scielo.br/scielo.php?pid=S0103-84782001000500031\&script=sci_abstract $>$ Acesso em: 02 out. 2017.

SILVA, Roberta Pereira da. Remoção de metais pesados em efluentes sintéticos utilizando vermiculita como adsorvente. 2010. 101 f. Tese (Doutorado) - Programa de Pós-Graduação em Ciência e Engenharia de Materiais da Universidade Federal do Rio Grande do Norte.

Natal, 2010. 
SIPPONEN, Mika Henrikki et al. Determination of surface-accessible acid hydroxyls and surface area of lignina cationic dye adsorption. Bioresource Technology, v. 169, p. 80-87, oct. 2014. Disponível

em:<https://www.sciencedirect.com/science/article/pii/S0960852414009274?via\%3Dihub\#!> Acesso em: 17 ago. 2017. 